intelligently alive to the necessity for keeping awake public consciousness, we will have given Framingham the very highest and best service. If we can have intelligent citizens to fight for the eradication of tuberculosis, we need have no fear for the future fight against the disease.

\section{Relative Values in Anti-Tuberculosis Work.}

By Professor C. M. Hilliard, Boston, Associate Professor of Biology and Public Health, Simmons College.

THE tuberculosis problem is one of the most complex and confusing of all public health problems, having many aspects which appeal in their relative importance with different emphasis to workers who may be specializing in their respective fields. It seems worth while, therefore, to attempt an analysis of the salient features of the campaign for the prevention of this scourge, and to try to attribute to each factor a certain weight which will indicate its relative importance. Such a method has been applied with great success to the general problem of public health work by Dr. Charles V. Chapin, George C. Whipple, Franz Schneider, and others, and it seems quite likely that a more intensive analysis of the problem of child hygiene, infant welfare, tuberculosis, and other health problems will throw light on what our course of procedure should be in the future. There is always a strong tendency for scientific progress to outstrip the practical application, and our whole knowledge of communicable disease, and the science of prevention, is so new and is growing so rapidly that we should frequently make an inventory to see where we stand. It is this idea which I have in mind when I attempt the difficult problem of contrasting the importance of different factors in the anti-tuberculosis campaign.

Tuberculosis has been the most important cause of death amongst civilized peoples as far back as we have reliable vital statistics. For this reason it has probably received more attention from the medical and sanitary professions than any other disease. Its prophylaxis may be compared with the different stages in the development of our knowledge of communicable diseases. The infectious nature of tuberculosis was established by Villemin in 1865 , almost two decades before the discovery of the tubercle bacillus by Koch. Prior to that time the nature of the disease was shrouded in mystery, it being looked upon as an hereditary disease, or as due to peculiar and unavoidable conditions of surroundings. With the definite knowledge of its communicability and with the accompanying sanitary awakening in England, which rapidly spread to other civilized nations at this time, a new epoch in combating the disease arose. It became apparent that this disease, as others, was associated with filthy human surroundings, and the attack was made in a hit-or-miss fashion upon dirt and decomposing matter.

With the demonstration of its specific etiology (1882), a new era arose. The foci of infection were very apparently associated with human beings suffering from the disease, and the hope was raised that at last a means of eradicating the disease had been discovered by preventing the spread of the germ from these centers. But in the last decade of the 19th century emphasis was being more and more concentrated upon cure. The establishment of the first sanatorium at Saranac by Dr. Trudeau in 1885 blazed the way to this new era, and the results which were immediately forthcoming were of an exceedingly hopeful character. It was definitely demonstrated that under the treatment given at sanatoria improvement of the patient rapidly followed. Still another element was added about this time (1890) by the discovery of tuberculin, and for a time it seemed as though a specific curative treatment would solve the problem. At the opening of the present century, a new appreciation of the social aspects of the disease arose, which led to the inauguration of the personal contact of the antituberculosis worker with the patient in his home. I refer to the inauguration of the public health nurse in 1904, although it is worth noting that in 1899 two medical students under the direction of Dr. Osler had done house-to-house work for the sake of educating the patient and family, and of putting the patient in contact with the proper organized social relief. (Gardner, "Public Health Nursing," p. 25.)

If we examine the death rate from tuberculosis over a long period of time and with large enough groups, the hopefulness of the measures that have been tried is not altogether inspiring. We find that tuberculosis has been on the decline as a cause of death for generations, and, as Pearson has pointed out, in England, at least, the rate of decline is less rapid 
during the last thirty years than it was during the previous thirty years. The discovery of the tubercle bacillus, the inauguration of the sanatorium, and even the recognition of the social and economic nature of the disease have not brought about any general measures which result in a sharp decline at those periods. It may well be argued that none of the measures has been tried on a sufficiently extensive scale to be a true measure of the prophylactic value of any one of these methods, and that is doubtless true up to a certain point, for we find in those cities and states where intensive work has been done that the death rates show a much sharper decline than for average and large populations. We might well say the decline in tuberculosis would result in spite of all of our prophylactic measures, rather than as a result of them.

At the present time, we are confronted the world over with conditions which may well be expected to raise the prevalence and the death rate from this terrible scourge. In fact, Newsholme has pointed out that in England and Wales the death rate from pulmonary tuberculosis during 1915 and 1916 is $12 \%$ greater than in 1913. (Lancet, 1917, ii). Newsholme states that "The experience in this country appears to coincide with that of the continental countries engaged in the present war." We are all familiar with the appalling situation in France as indicated by Dr. Biggs' report. The same thing is already indicated in the death rates in New York City from this disease, where the rate had steadily declined from 1.81 in 1910 to 1.50 in 1916, but showed a marked increase in 1917. The first eleven months of 1916 showed 7685 deaths; for the same period 1917 there were 8092 deaths from pulmonary tuberculosis. Dr. Kerr, health officer of Newcastleupon-Tyne, likewise indicates the trend of this disease and states "that considerable increase in the number of deaths among that section of a civil population which has been especially af. fected by the new conditions of life brought about by the war, namely, girls at ages between 15 and 20 years," is shown.

The total deaths from pulmonary tuberculo. sis are shown from the following table by Kerr :

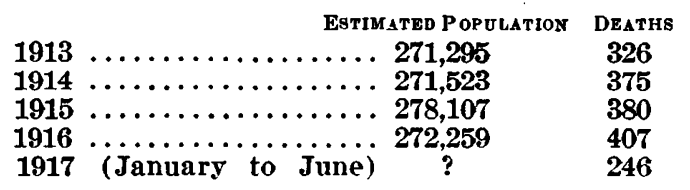

It becomes doubly imperative, then, that we should expend our energies in the present emergency in the most fruitful manner.

The prophylactic measures used to combat tuberculosis may" conveniently be classified under four general headings: the prevention of infection; the cure of the disease; the predisposing factors; and public health nursing. Be fore we try to weight these various factors, we may well go into a consideration of each in some detail.

\section{INFECTION.}

The overwhelming evidence at the present time is that the tubercle bacillus is an almost ubiquitous organism in the body of man. The well-known investigations by Naegeli showed that upon necropsy at least $99 \%$ of persons harbor this microbe in their bodies by the age of 30 . More recent work by Reinhardt in Switzerland demonstrated 347 out of 360 consecutive autopsies, or $96 \%$, to be tuberculous. The von Pirquet reaction confirms in general the results that are found after death. More significant, possibly, is the early age at which infection occurs. In New York, in 1320 autopsies of children under the age of $5,13.5$ showed more or less generalized tuberculosis. According to the cutaneous test, which is generally admitted to be fairly reliable in children, from 80 to $90 \%$ seem to have contracted the disease before the 14th year. Knopf (New York Medical Journal, 1917, ev, p. 1181) gives the following analysis for the age at which infection occurs :

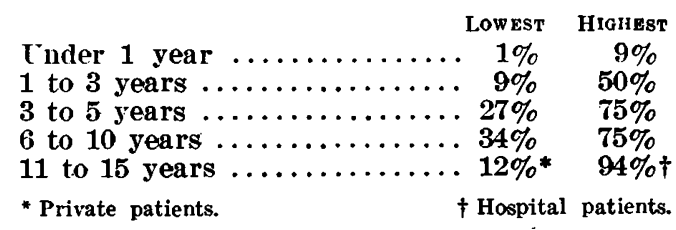

Without giving further figures which might be abundantly quoted, it becomes apparent that the problem of absolutely preventing infection during life is a vast one, and since relatively so small a number of persons acquire the disease in its active form, it likewise leads to the conclusion that infection is perhaps not the solution of the problem. An organism which is so generally distributed and seeded in the human race as this is almost as difficult to eradicate as the colon bacillus, which appears in the intestines of the newly born babe usually a few hours after birth; or mouth streptococci, 
which are likewise found in the mouth very early after birth.

The mode of infection in this disease is somewhat obseure. The tubercle bacilli which infect man seem to have two primary sources: the discharges from the lungs of the tuberculous, and animals suffering from the bovine type of bacillus. As to how the organism enters the body is subject to controversy. The older theory regarding aerogenic infection has been supplemented by the ingestion theory. Doubtless, infection may occur by the. direct inhalation of fresh dry, and pulverized sputum found in dust, or in sputum particles ejected during coughing and spitting, but organisms taken in this manner into the nose and throat may quite likely, instead of going directly to the lung tissue, penetrate through the tonsils, and be conveyed to their final destination via the lymphatics, or they may even be swallowed, and enter through the intestinal tract to the mesentery glands, and may be transported from there to the lungs. It seems more casy, now that we know about the scarcity of pathogenic microbes in the air and their survival here, that tubercle bacilli more commonly are taken into the body with food or upon articles that are infected with sputum. Infection by the alimentary portal has been demonstrated to be a possibility, and it may enter without leaving any trace as a primary infection. The common location of the primary infection in the apex of the lungs suggests other than the respiratory passage. Referring to the organism which comes from animal origin,- - notably cows' milk,-there is no question but what its common path of invasion is through the alimentary canal. This type of disease is most common in children, and is easily preventable by the rou. tine practice of efficient pasteurization of all milk.

The prevention of infection, then, resolves itself, first of all, into the problem of preventing the contamination of surroundings with sputum and saliva. The anti-spitting ordinances are a beginning in this line of prevention, but vastly more important is the general education of people to the importance of other means of exchanging saliva. Masses of sputum expelled to the ground or floor, even in public places, are much less liable to return to persons in fresh form than as though this material were sprayed into the atmosphere in coughing and sneezing, or were smeared by fingers upon trolley straps, door knobs, counters, drinking cups, and eating utensils, or upon food, such as bakery products.

The danger from these latter sources is indicated by the recent study in New York City, where an intensive examination of food handlers revealed that out of 1748 persons "there were 10 cases of active tuberculosis, 12 of suspected and 3 arrested tuberculosis." The early diagnosis of cases to prevent active foci of the disease, the hospitalization of active cases, thorough disinfection of the discharges, proper instruction of both patient and attendants and exposed persons, and the exclusion of the tuberculous from employment in industries involving the handling of food, aid in preventing the spread of the disease. We emphasize these things in spite of the fact that we have indicated that to avoid infection during lifetime is rather hopeless, because we definitely understand that repeated infection and massive infection may at any time be a danger.

\section{CURE.}

That tuberculosis in its early stages is a dis. ease that may be arrested, and perhaps permanently arrested, is a well-demonstrated fact. Cure, in the sense that the bacilli may be eradicated from the body, is conceded to be quite improbable. The secret to the cure of the disease is its early detection, and any measures that will encourage the early detection of the disease are not only in favor of the patient, but in favor of the public health. The encouragement of routine physical examination for school children, for adult employees, and for all persons is an anti-tuberculosis measure of first magnitude. We should discard the secrecy that surrounds this disease and should report it frankly to public health authorities, to the family, and to the patient himself, immediately the suspicion arises. To conceal the disease from the patient or from others is to deny the opportunity for cure and subsequently to endanger the public health.

With the discovery of tuberculosis in the pa. tient, proper instruction and proper facilities for the treatment should at once be found. We are laying less and less emphasis upon the importance of climate, latitude, and altitude, and more and more upon rest, and cheerfulness, and successful nutrition of the patient. Out-ofdoor air is apparently quite as good for tuberculosis patients in New England as it is in 
Colorado. The cure has a .psychological ele. ment as well as physiological. The sanatorium, likewise, is not indispensable in the program for cure, although each case must be considered separately in this regard. Fishberg (1916) says: "It is shown that institutional treatment is not the only, nor the best method of caring for the majority of patients." If the case is not yet a menace to the family (with the exception of cases where the facilities cannot be devised for home treatment) they should be encouraged to remain at home. The sanatorium is for the very poor and the ignorant, primarily. Out-of-door schools, not only for recognized cases, but for all children with poor physique, should be rapidly extended. The tuberculin treatment would be included as a hopeful item by many, and with our increase in the knowledge of administering this agent it may become an important item.

\section{PREDISPOSING FACTORS.}

Vigorous physiologic defense is the secret in combating tuberculosis, and social and economic factors play the largest part in the maintenance of high resistance. Granting the presence of a benign and almost universal infection with tuberculosis, the occurrence of the disease in its active form, chiefly in the age period from twenty to forty, must be explained either on the basis of radical reinfection between these ages or to a flaring up of the latent lesion into an active form. The habits of life and industry at this time seem not to afford unique opportunities for further or more massive infection. At this period, however, the entrance into industry, the intense ambition to acquire position, power or money, and the increased exposure to temptation all lend to cumulative fatigue and lowered power of defense. "Chronic fatigue, whether from excessive toil or excessive amusement; disordered metabolism, whether from starvation or over-indulgence; anxiety, whether due to religious fervor, business emergencies or games of chance, all are predisposing factors."*

The general predisposing factors of a social and economic character are so numerous that it will be useless to attempt to consider them all separately. Broadly speaking, all factors that lead to fatigue and depletion contribute to tuberculosis. We shall discuss a few predisposing factors specifically. Inheritance, both

* Smith: Jour. A. M. A., Ixvi, pp. 77.82 racial and family, plays an important part. In relation to prophylaxis, however, but little can be done through heredity. In families where tuberculosis is known to be present in active form, restriction of the increase in the family might be discreetly urged through legislation and through education; and marriage between parties, one or the other being tuberculous, may be prevented.

Malnutrition, especially among children, is a most important item. We learn from a recent number of the New York City Weekly Bulletin that approximately one-eighth of all school children in the city are undernourished, or 125,. 000 . We need only to look around us to see the perpetual demonstration of how common insufficient nutrition is in the human race, and to appreciate that a vast problem confronts us here which plays its rôle in tuberculosis. The present status of the food situation in America and throughout the world is rather discouraging from one standpoint, but from another, namely, that for the first time the public is being informed as to what constitutes an ade quate diet, it is, perhaps, encouraging. At this time let us make sure that we feed our infants and our growing boys and girls well.

Alcoholism, other drug addictions, and all excesses tend towards tuberculosis.

Tuberculosis has been called an "occupational disease," and the more we learn of the relation of tuberculosis to industry the more we appreciate the truth of this. This is very hopeful because most of the industrial conditions that predispose to tuberculosis may be corrected. The trades which are most dangerous are: first, all of those which expose the worker to dust; secondly, those where bad air, excessive heat, and noxious gases occur; and, finally, the occupations where the poor posture and close confinement are common. Dr. Crumb, in analyzing the Prudential Life Insurance Company's experiences, finds that in dusty trades the death rate is from twenty to thirty per cent. higher than in non-dusty occupations for all workers. In an exhaustive study of the factors contributing to the incidence of tuberculosis in Cincinnati, Robinson and Wilson conclude that occupational hazard is one important contributory cause. The elimination of child labor, minimum wage scale, health insurance, and other sociological industrial elements are highly important.

There are certain diseases which directly pre- 
dispose to tuberculosis, which are themselves preventable. Typhoid fever is most significant in this respect. In a notable paper Dr. Woodruff has shown the parallel decline in typhoid and tuberculosis in many countries. The past histories of sanatorium inmates show that they have suffered from typhoid fever in excess of the general population. All acute or chronic diseases lower resistance and throw wide the portal to the tubercle bacillus. Pertussis, measles, and scarlet fever seem to render children particularly liable. General sanitation and disease prevention are, therefore, weapons against tuberculosis.

Housing conditions are usually included as predisposing causes. House infection in the sense that the house becomes infected and seeded with tuberculous bacilli, and that infection is contracted readily because of such conditions, probably is not important. It is, however, certainly true that tuberculosis increases in direct ratio to number of persons per room. Bad housing goes hand in hand with poverty, poor human protoplasm, ignorance, alcoholism; and tuberculosis is the result of a long sequence of conditions rather than the room or house.

Poverty itself is a predisposing cause. If we could eradicate poverty we should go a long way toward eradicating tuberculosis. We usually state hopelessly that the poor are always with us, and to combat poverty is to combat the foundations of society, and with its eradication would come the millennium. Much can be done in the way of eradicating poverty by education, the minimum wage scale, the social and health insurance, institutional aid, and brotherly love.

PUBLIC HEALTH NURSING AND EDUCATION.

We now come to the last of the four items which we are to discuss, and, historically, we find that it is the latest to develop. Public health nursing in relation to tuberculosis has the following objects: prevention of the spread of infection and detection of new cases; the instruction and nursing of patients at home, cooperation with agencies which may help the patient; assistance at clinics and dispensaries. We see at once that her work is very broad; that it is chiefly social and educational, ameliorating those factors which we have insisted upon before as being most important in the anti-tuberculosis work. Dr. McLaughlin has said that "dollar for dollar the public health nurse will give more for the money than any other single agent," and this is emphatically true in tuberculosis.

Education is the keynote to the nurse's work. It is by gradual, quiet instruction that she teaches the patient how to avoid infecting the environment, and the family how to protect itself. It is through instruction rather than nursing, which is really only in the form of a demonstration, that the patient is given the proper care at home. The finding of new cases is; of course, to give the patient the benefit of early treatment and the community the apportunity to rid itself of one dangerous focus of infection. The nurse seeks to place patients and families in contact with clinies, hospitals, and sanatoria when the need arises. She helps the discharged patient to rehabilitate himself, and is on guard for recurrence of the disease. Her work in relation to the health supervision of school children is recognized as indispensable. In combating tuberculosis in rural communities, the nurse is the strategic element; in fact, the only agency which has appeared. Her services are too little appreciated and too few facilities, as adequate facilities for travel, are given her to perform efficiently her tasks. The work of the medical social service worker, the industrial nurse and the infant welfare nurse verges upon, and, in fact, is a part of the antituberculosis program. We cannot lay too much emphasis upon the hopeful character of the nurse's work in the campaign for reducing the scourge.

We now approach the difficult task of assigning the relative numerical values to the different factors which we have discussed. In its entirety the tuberculosis work is rated at $14 \%$ of the total by Chapin, as $12.1 \%$ by Schneider. In the effort to get an accurate measure of the influence of any one, or any group of these factors, we have been unable to work out a mathematical system. The figures simply represent an arbitrary weight. The items obviously overlap, sometimes one measure being worthless without another, as in the detection of new cases, reporting and subsequent treatment. From the preventive viewpoint, to recognize the case early is more important than the sort of treatment rendered. The weight of a given factor or agency has been considered from its response to corrective measures as well as the number of cases of the disease involved. Thus, 
racial inheritance may play a large part; poverty is the very background for tuberculosis, and yet neither responds easily to applied prophylactic measures. Dusty trades, though not involving any large proportion of all cases of tuberculosis, are largely preventable. The nurse's work is a corollary of most of the other items listed, and her influence would be nullified in the absence of the clinic, the "preventorium,' and other agencies.

The educational work of the public health nurse ranks first in prophylaxis. Unlimited protection from infection in early life, arbitrarily, up to the age of four years, and the control of the elements of malnutrition and fatigue each rank high in our estimate, these four items totaling nearly one-half the total score. It is our feeling that if those elements that are weighted high are emphasized the lesser factors will automatically fall in line.

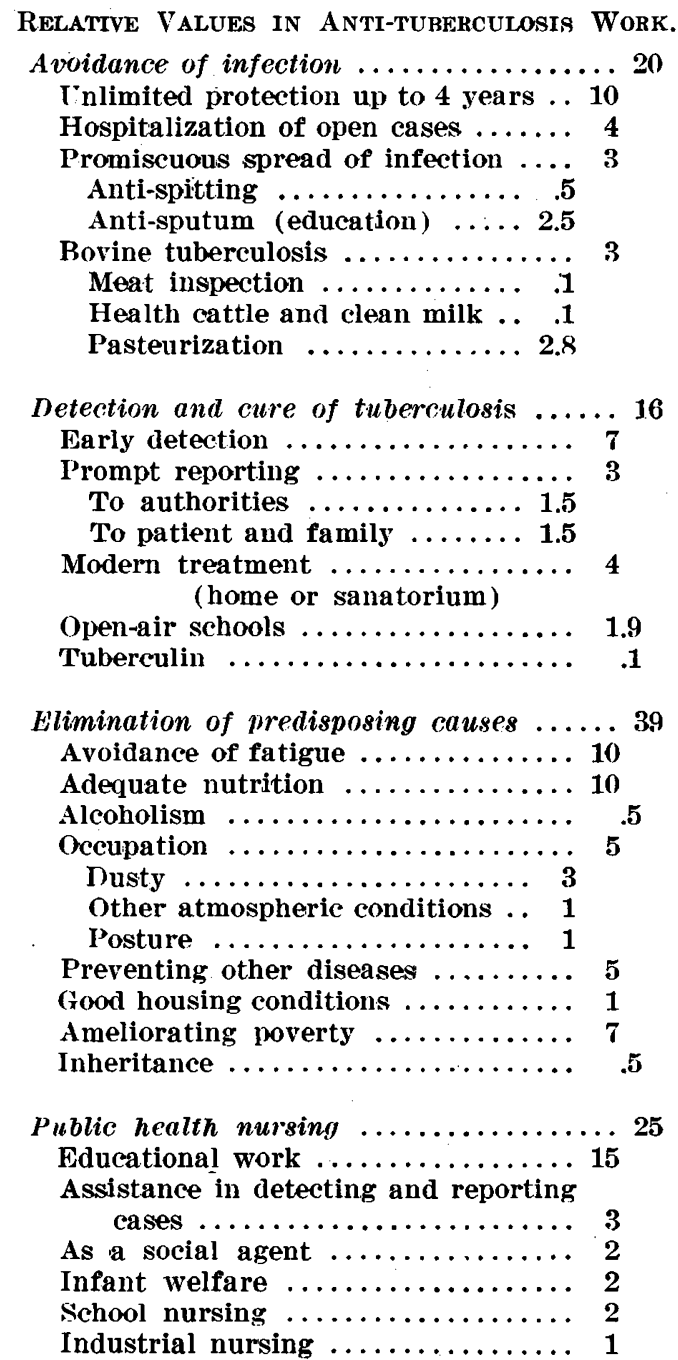

Annual Report of the Massachushtts ANTiTuberculosis League, 1918.

By Grhel M. Spofford, Roston,

Acting secretary.

IN the absence of our Executive Secretary, Mr. Seymour H. Stone, who has been granted an indefinite leave of absence for the duration of the war and is now associated with the War and Navy Department Commissions on Training Camp Activities in Community Organization, I am going to give you a summary of the year's work.

\section{EDUCATIONAL AND FUBLICITY.}

During the last year almost 27,000 pieces of literature were distributed. This large amount is due to a new leaflet, "Facts for Fighters," which was prepared especially for enlisted men and sent to the Massachusetts cantonments and exemption boards wherever there was a chance for distribution. A set of six educational articles on tuberculosis, to be used for copy in schools of stenography, were purchased by the League and are gladly furnished to any schools who would care to use them. Over 6000 Press Bulletins from the National Tuberculosis Association, mostly dealing with tuberculosis, were sent to city and state newspapers. A booklet on sleeping and sitting out was sent to medical men and others interested in tubereulosis. The balance of the literature distributed included circulars and pamphlets of an educational nature, programs and reports of the annual meeting. Along the lines of educational work, it might be added that our President was very successful in arranging a series of lectures given by men well known in the medical pro. fession to the military doctors at Camp Devens. These were very well received. The question of lecturing to enlisted men came up, but the League was of the opinion that it would be a mistake for civilian doctors to endeavor to address the enlisted men. During February and March this year the League was glad to coöperate with the National Association in its membership drive to obtain 5000 new members.

\section{LEGISI _ATION.}

There were few general bills of importance before the Legislature of 1917 of immediate bearing on tuberculosis, and the same is true of the Legislature of 1918 .

Probably the most important measure affect- 